\title{
Modeling of Flow Stress of 2026 Al Alloy under Hot Compression
}

\author{
Zheng-bing Xiao, ${ }^{1,2}$ Yuan-chun Huang, ${ }^{1,3}$ and Yu Liu ${ }^{3}$ \\ ${ }^{1}$ School of Mechanical and Electrical Engineering, Central South University, Changsha 410083, China \\ ${ }^{2}$ Collaborative Innovation Center of Advanced Nonferrous Structural Materials and Manufacturing, \\ Central South University, Changsha 410083, China \\ ${ }^{3}$ Light Alloy Research Institute, Central South University, Changsha 410012, China
}

Correspondence should be addressed to Zheng-bing Xiao; xiaozb@csu.edu.cn

Received 25 February 2016; Accepted 17 July 2016

Academic Editor: Sutasn Thipprakmas

Copyright (C) 2016 Zheng-bing Xiao et al. This is an open access article distributed under the Creative Commons Attribution License, which permits unrestricted use, distribution, and reproduction in any medium, provided the original work is properly cited.

In order to investigate the workability and to optimize the hot forming parameters for $2026 \mathrm{Al}$ alloy, hot compression tests were performed in the temperature range of $350 \sim 450^{\circ} \mathrm{C}$ with strain rates of $0.01 \sim 10 \mathrm{~s}^{-1}$ and $60 \%$ deformation degree on a Gleeble-1500 thermosimulation machine. The true stress-strain curves obtained exhibit that the stress increases dramatically at small strains and then moves forward to a steady state, showing dynamic flow softening. Meanwhile, on the basis of Arrhenius equation, a constitutive equation on the flow stress, temperature, and strain rate was proposed. Yet, the values of the predicated stress from the equation and the true stress differ by as much as $50.10 \%$. Given the intricate impact of precipitation of the second phases on the strength of $2026 \mathrm{Al}$ alloy, the introduction of a revised equation with the reinforcement of temperature was carried out, fitting well with the experiment data at peak stresses. What is more, both pictures obtained by scanning electron microscopy (SEM) and transmission electron microscopy (TEM) were compatible with all the inferences.

\section{Introduction}

Understanding the materials flow behavior during hot deformation is important for materials processing designers, especially for those dealing with metal processes like hot forging, rolling, and extrusion [1-3]. Usually, constitutive equations describing relationships on the strain rate, temperature, and flow stress, which can be used in the finite element simulation, are helpful in selecting the appropriate working parameters for a given metal to process. A great deal of investigation had attempted to set up constitutive equations to predict the flow stress, especially for the frequently used alloys like aluminum alloys, steels, and nickel based super alloys [4-10]. Generally, constitutive models now used can be classified into phenomenological type, physical-based type, and artificial neural network (ANN) type [11]. The Arrhenius equation of phenomenological type was the main one for its simplicity and accuracy $[6,12-16]$. Numerous papers have been published based on the equations proposed by Sellars and Zener [17-19], either the constitutive equations or the modified ones, especially in the hot working of steels, all agreeing well with experiment results, assisting in selecting the hot deformation parameters [12, 20-27].

But, unlike steels, microstructures of aluminum alloys will significantly change due to precipitation in the hot deformation processing, not to mention that those can be strengthened by heat treatment, $2 \mathrm{xxx}$ and $7 \mathrm{xxx}$ alloys, for example, which usually serve as skins and frames of airplanes. Second phases, like $\mathrm{Al}_{2} \mathrm{Cu}$ in $2 \mathrm{xxx}$ alloys and $\mathrm{MgZn}_{2}$ in $7 \mathrm{xxx}$ alloys, usually appear in the hot working and heat treatment, which need substantial increase of the stress to continue the hot deformation [15, 28-32]. Prediction of the peak stress for those alloys is hard for their temperature-dependent nature, but the stress-strain relationship, especially the peak stress, is crucial for processing, since it determines the selection of the machines to fulfill the upper compressive stress needed.

As an improved version of $2024 \mathrm{Al}$ alloy, $2026 \mathrm{Al}$ alloy with lower Fe and Si content but minor addition of $\mathrm{Zr}$ to 
inhibit recrystallization during hot working was established by Alcoa in 1999, satisfying demand for better safety and durability without sacrifice of strength and toughness [33]. As a new alloy of high strength and high damage tolerance, 2026 $\mathrm{Al}$ alloy is used as the upholstery skin material for lower aero foil in airplanes like A380 from hot rolling.

Unlike the traditional materials, works about $2026 \mathrm{Al}$ alloy are rare to find, and the most existent investigations on $2026 \mathrm{Al}$ alloy mainly focus on the microstructure evolution during hot processing or the precipitation of the second phases [33, 34]. To the authors' knowledge, there is little information available in the literature about flow behavior of $2026 \mathrm{Al}$ alloy; further study is needed to perform numerical simulation and to select proper process parameters. This paper will put forward and verify a new constitutive equation about the flow behavior of $2026 \mathrm{Al}$ alloy under hot deformation.

\section{Experiments}

A commercial $2026 \mathrm{Al}$ alloy of chemical composition (wt.\%) 1.33Mg-4.20Cu-0.55Mn-0.15Zr-(bal.)Al, with minor elements like Si and Fe below 0.05 and 0.07 (wt.\%), respectively, was used in the investigation. Specimens were prepared with diameter of $10 \mathrm{~mm}$ and height of $15 \mathrm{~mm}$ from the direct cast ingot homogenized for $490^{\circ} \mathrm{C} \times 12 \mathrm{~h}+520^{\circ} \mathrm{C} \times$ $12 \mathrm{~h}$. Friction between the specimens and upsetting dies was minimized by entrapping the lubricant with composition of $75 \%$ graphite $+20 \%$ machine oil $+5 \%$ nitric acid trimethyl benzene grease in a depth of $0.1 \mathrm{~mm}$ recessed into both ends of the specimens.

As depicted in Figure 1, the specimens were heated to $480^{\circ} \mathrm{C}$ at a heating rate of $2^{\circ} \mathrm{C} / \mathrm{s}$ and held for $6 \mathrm{~min}$ and then cooled to the deformation temperature at $10^{\circ} \mathrm{C} / \mathrm{s}$ and held for $4 \mathrm{~min}$ before test. The hot compression tests were carried out on a Gleeble-1500 thermosimulation machine at four different strain rates $\left(0.01 \mathrm{~s}^{-1}, 0.1 \mathrm{~s}^{-1}, 1 \mathrm{~s}^{-1}\right.$, and $\left.10 \mathrm{~s}^{-1}\right)$ and four different temperatures $\left(300^{\circ} \mathrm{C}, 350^{\circ} \mathrm{C}, 400^{\circ} \mathrm{C}\right.$, and $450^{\circ} \mathrm{C}$ ), with $60 \%$ final reduction in height. After the hot compression, specimens were quenched in water immediately for micrographic observation.

\section{Results and Discussion}

3.1. True Stress and Strain. The true stress-strain curves obtained from hot compression tests for $2026 \mathrm{Al}$ alloy are shown in Figure 2. For aluminum alloys of high stacking fault energy, dynamic recovery is the main reason for the softening phenomenon [35], which is confirmed by the occurrence of dynamic softening on the curves in this work, for the flow stresses increase monotonically up to an almost steady state (e.g., samples deformed at strain rate of $0.01 \mathrm{~s}^{-1}$ ). As can be seen from the figures, the strain rate and temperature significantly affect the flow stresses. The true stress level will rise once deformation temperature decreases and strain rate increases.

Under low temperatures, restraint of the number of slip systems reduces the mobility at grain boundaries, thus

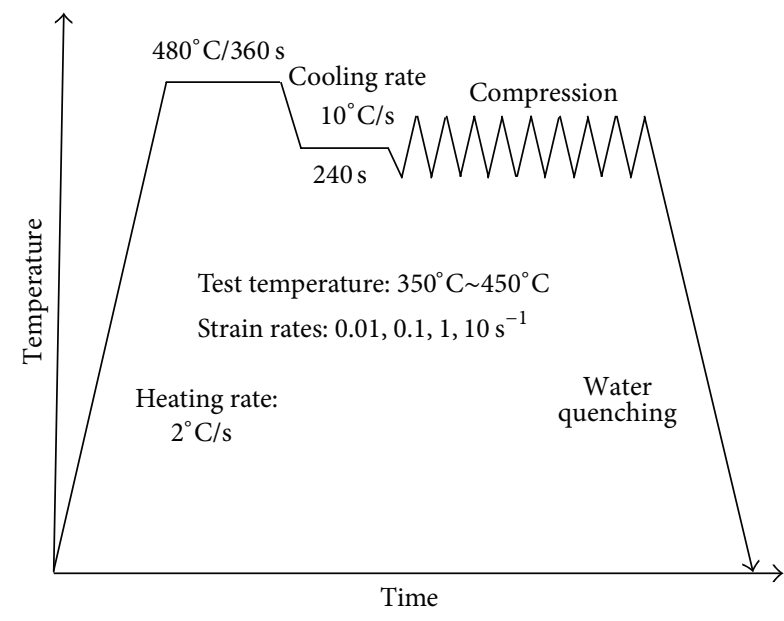

FIGURE 1: Experimental procedure for hot compression tests.

increasing the flow stress. This was approved further by the dislocation walls in Figure 3, for the TEM observation of the sample at $300^{\circ} \mathrm{C} / 10 \mathrm{~s}^{-1}$, which shows the highest flow stress during compression.

By raising the deformation temperature, dislocation slip, climb, and annihilation correspondingly increase, together with vacancy diffusion rate, resulting in easier activation of dynamic recovery and even dynamic recrystallization to overcome the hardening. Figure 4 shows, for the sample deformed at $0.01 \mathrm{~s}^{-1} / 450^{\circ} \mathrm{C}$, subgrains formed at grain boundaries, evidence of dynamic recrystallization, which can greatly contribute to the decrease of the flow stress. However, with the increase of strain rate, the time for energy accumulation, dynamic recovery, and recrystallization is shortened, and the true stress would increase.

3.2. Deformation Constitutive Equation. Usually, the relationship regarding flow stress, deformation temperature, and strain rate can be expressed by Arrhenius equation. Zener-Hollomon parameter $Z$ in an exponent-type equation represents the effects of strain rate and temperature on the deformation behaviors. Consequently, Arrhenius equation can be used to connect $Z$ parameter with stress [18, 19]. Hence,

$$
\begin{aligned}
& Z=\dot{\varepsilon} \exp \left(\frac{Q}{R T}\right) \\
& \dot{\varepsilon}=A F(\sigma) \exp \left(-\frac{Q}{R T}\right),
\end{aligned}
$$

where

$$
F(\sigma)= \begin{cases}\sigma^{n^{\prime}} & \alpha \sigma<0.8 \\ \exp (\beta \sigma) & \alpha \sigma>1.2 \\ \sinh (\alpha \sigma)^{n} & \forall \sigma,\end{cases}
$$




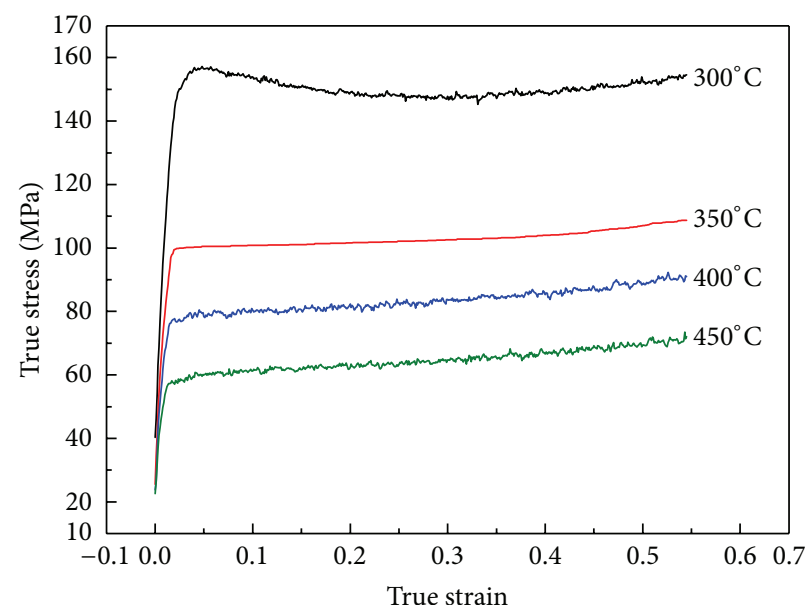

(a)

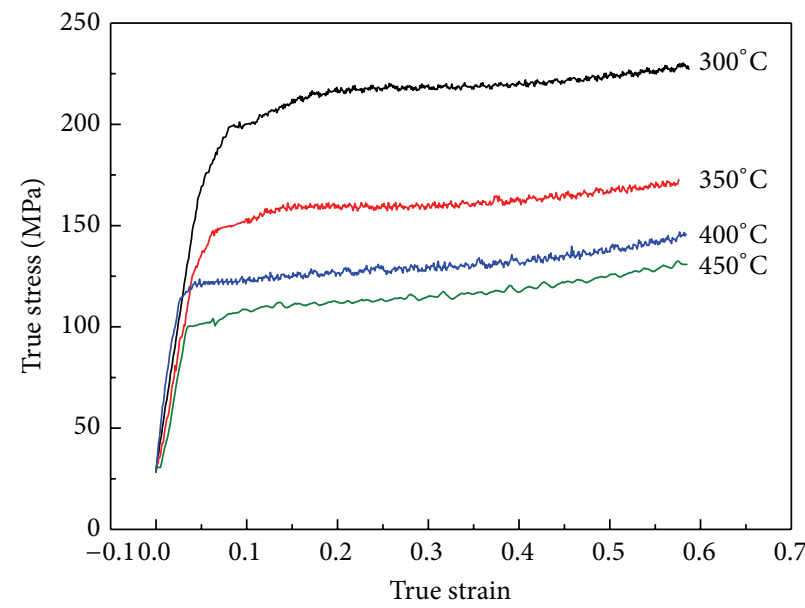

(c)

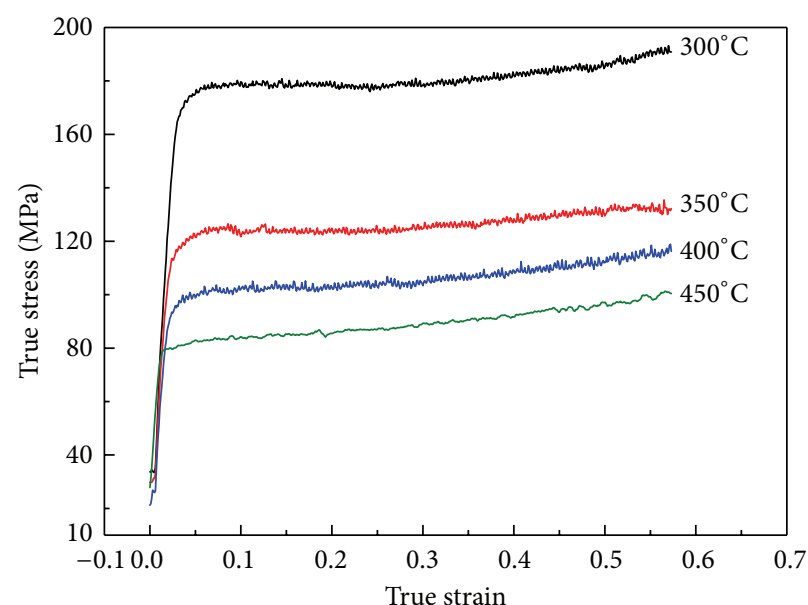

(b)

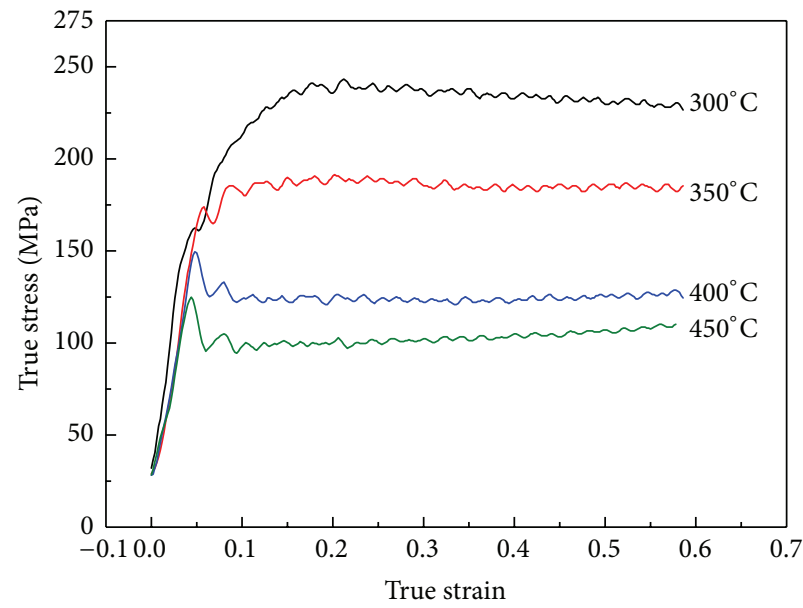

(d)

FiguRE 2: Typical true stress-strain curves for $2026 \mathrm{Al}$ alloy under different deformation temperatures with strain rates of (a) $0.01 \mathrm{~s}^{-1}$; (b) $0.1 \mathrm{~s}^{-1}$; (c) $1 \mathrm{~s}^{-1}$; and (d) $10 \mathrm{~s}^{-1}$.

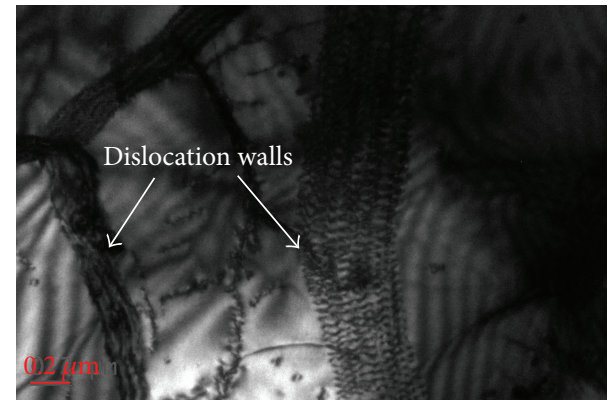

FIGURE 3: TEM micrograph of the sample deformed at temperature of $300^{\circ} \mathrm{C}$ with the strain rate of $10 \mathrm{~s}^{-1}$ with dislocation walls.

in which $\dot{\varepsilon}$ is the stain rate $\left(\mathrm{s}^{-1}\right), Q$ is the activation energy of hot deformation $\left(\mathrm{kJmol}^{-1}\right), R$ is the universal gas constant $\left(8.31 \mathrm{Jmol}^{-1} \mathrm{~K}^{-1}\right), T$ is the absolute temperature $(\mathrm{K})$, and $\sigma$ is the flow stress (MPa) for a given strain, while $A, \alpha$, and $n, n^{\prime}$ are the material constants, $\alpha=\beta / n^{\prime}$.
Equations (4) and (4) are the substitution of the power law and exponential law of $F(\sigma)$ into (1) for the low-stress $(\alpha \sigma<$ $0.8)$ and high-stress level $(\alpha \sigma>1.2)$, respectively:

$$
\begin{aligned}
& \dot{\varepsilon}=B \sigma^{n^{\prime}}, \\
& \dot{\varepsilon}=B^{\prime} \exp (\beta \sigma) \frac{1}{2},
\end{aligned}
$$

where $B$ and $B^{\prime}$ are the material constants. To find out the material constants in the above equations, deformation strain of peak stress is used here as an example.

Equations (6) and (6) are the logarithm form of (4) and (4), respectively:

$$
\begin{aligned}
\ln (\sigma) & =\frac{1}{n^{\prime}} \ln (\dot{\varepsilon})-\frac{1}{n^{\prime}} \ln (B), \\
\sigma & =\frac{1}{\beta} \ln (\dot{\varepsilon})-\frac{1}{\beta} \ln \left(B^{\prime}\right) .
\end{aligned}
$$

Substituting the values of the peak stress and corresponding strain rate at different deformation temperatures into (6) 


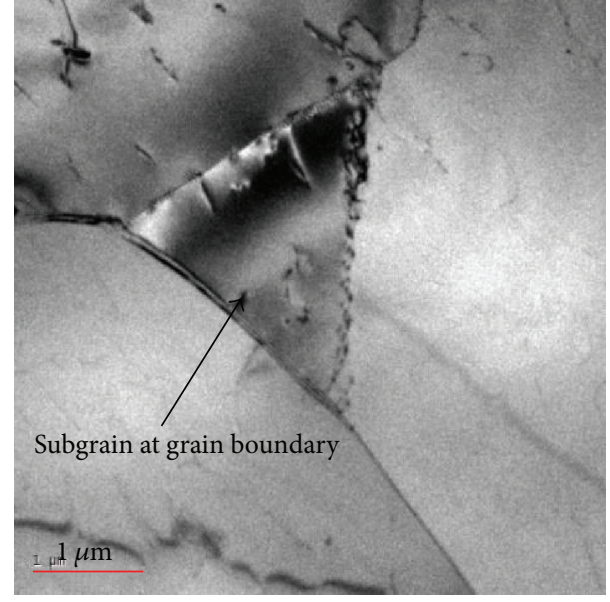

FIGURE 4: TEM micrograph of the sample deformed at temperature of $450^{\circ} \mathrm{C}$ with the strain rate of $0.01 \mathrm{~s}^{-1}$.

and (6) can obtain the relationship regarding the stress and strain rate (in logarithm form) shown in Figure 5.

As can be seen in Figure 5, a group of straight lines approximated is close to parallel. The slopes of these lines have similar values and values of $n^{\prime}$ and $\beta$ at different deformation temperatures can be derived by linear fitting method. As $\alpha=\beta / n^{\prime}$, each corresponding value of $\alpha$ can be calculated. By average, the mean value of $\alpha$ is $8.0128 \times 10^{-3}$.

Equation (1) can be expressed as follows, fit for all the stress level $\sigma$ :

$$
\dot{\varepsilon}=A[\sinh (\alpha \sigma)]^{n} \exp \left(-\frac{Q}{R T}\right) .
$$

Taking the logarithm of (8) for both sides gives

$$
\ln [\sinh (\alpha \sigma)]=\frac{\ln \dot{\varepsilon}}{n}+\frac{Q}{n R T}-\frac{\ln A}{n} .
$$

Substituting the peak stress and relevant strain rate for all the tested temperatures into (9) gives the relationship shown in Figure 6. It is not hard to obtain the value of $n, 9.343$.

For a fixed strain rate, derivative of (8) gives

$$
Q=R n \frac{d\{\ln [\sinh (\alpha \sigma)]\}}{d(1 / T)} .
$$

According to (10), $\ln [\sinh (\alpha \sigma)]$ can be regarded as a function of $1 / T$, shown in Figure 7 , and the activation energy can be computed as $229.546 \mathrm{~kJ} / \mathrm{mol}$ by averaging the values of $Q$ at four different strain rates.

On the basis of the value of $n$ and $Q$ known, it is easy to get the value of $A, 5.17 \times 10^{22} \mathrm{~s}^{-1}, 9.53 \times 10^{22} \mathrm{~s}^{-1}, 8.3 \times$ $10^{22} \mathrm{~s}^{-1}$, and $3.63 \times 10^{22} \mathrm{~s}^{-1}$ for $300^{\circ} \mathrm{C}, 350^{\circ} \mathrm{C}, 400^{\circ} \mathrm{C}$, and $450^{\circ} \mathrm{C}$, respectively.

Then, (8) can be expressed below by substituting the values obtained above:

$$
\begin{aligned}
& \dot{\varepsilon}= A\left[\sinh \left(8.0128 \times 10^{-3} \sigma\right)\right]^{9.343} \\
& \cdot \exp \left(\frac{-2.29546 \times 10^{5}}{R T}\right) .
\end{aligned}
$$

Finally, Zener-Hollomon parameter $Z$ in (1) can be represented as follows:

$$
\begin{aligned}
Z & =\dot{\varepsilon} \exp \left(\frac{2.29546 \times 10^{5}}{R T}\right) \\
& =A\left[\sinh \left(8.0128 \times 10^{-3} \sigma\right)\right]^{9.343} .
\end{aligned}
$$

According to (8) and (1), relationships between the flow stress $\sigma$ and Zener-Hollomon parameter $Z$ can be described below:

$$
\sigma=\frac{1}{\alpha} \ln \left\{\left(\frac{Z}{A}\right)^{1 / n}+\left[\left(\frac{Z}{A}\right)^{2 / n}+1\right]^{1 / 2}\right\} .
$$

Or

$$
\sigma=124.8 \ln \left\{\left(\frac{Z}{A}\right)^{1 / 9.343}+\left[\left(\frac{Z}{A}\right)^{2 / 9.343}+1\right]^{1 / 2}\right\} \text {. }
$$

Depending on the deformation temperature, the constant $A$ in (11) to (14) is $5.17 \times 10^{22} \mathrm{~s}^{-1}, 9.53 \times 10^{22} \mathrm{~s}^{-1}, 8.3 \times 10^{22} \mathrm{~s}^{-1}$, and $3.63 \times 10^{22} \mathrm{~s}^{-1}$ for $300^{\circ} \mathrm{C}, 350^{\circ} \mathrm{C}, 400^{\circ} \mathrm{C}$, and $450^{\circ} \mathrm{C}$, respectively.

3.3. Modification of Zener-Hollomon Parameter. The abovedeveloped constitutive equations for $2026 \mathrm{Al}$ alloy at peak stress state were verified by comparison of the values from experiments and constitutive equation; differences between them are shown in Table 1. In the table, error is defined as

$$
\text { Error }=\frac{\left|\sigma_{c}-\sigma_{m}\right|}{\sigma_{m}} \times 100 \% .
$$

$\sigma_{c}$ is the stress calculated by the constitutive equation, and $\sigma_{m}$ is the peak stress measured by experiments.

Apparently, errors between the experiment and predicated results range from $9.86 \%$ to $50.10 \%$, indicating the need to modify the constitutive equation.

Usually, four different stages, namely, work hardening stage (stage 1), stable stage (stage 2), softening stage (stage 3 ), and steady stage (stage 4), show up on the true straintrue stress curves of typical steels, which can be explained well from the viewpoint of dynamic recovery and dynamic recrystallization under hot deformation [36, 37]. However, for almost all of the $\mathrm{Al}$ alloys, precipitation of the second phases inevitably occurs in the hot deformation procedure; $2026 \mathrm{Al}$ alloy is no exception. From Figure 8, the SEM and TEM microstructures of the sample deformed at $350^{\circ} \mathrm{C}$ with the strain rate of $1 \mathrm{~s}^{-1}$ and the final strain of 0.6 ; the matrix was occupied by numerous tiny white particles (most of them are $\mathrm{Al}_{2} \mathrm{Cu}$ ), a combining effect of temperature and strain whose influence on flow stress cannot be neglected.

Theoretically, by hindering recrystallization or being coherent with $\alpha$-Al, precipitation can enhance the material strength to some degree, reflected by the rise of the true stress level on the true stress-true strain curve $[33,34]$. Typically speaking, precipitation itself is a complicated factor whose impact on the true stress is relevant to temperature. Therefore, 


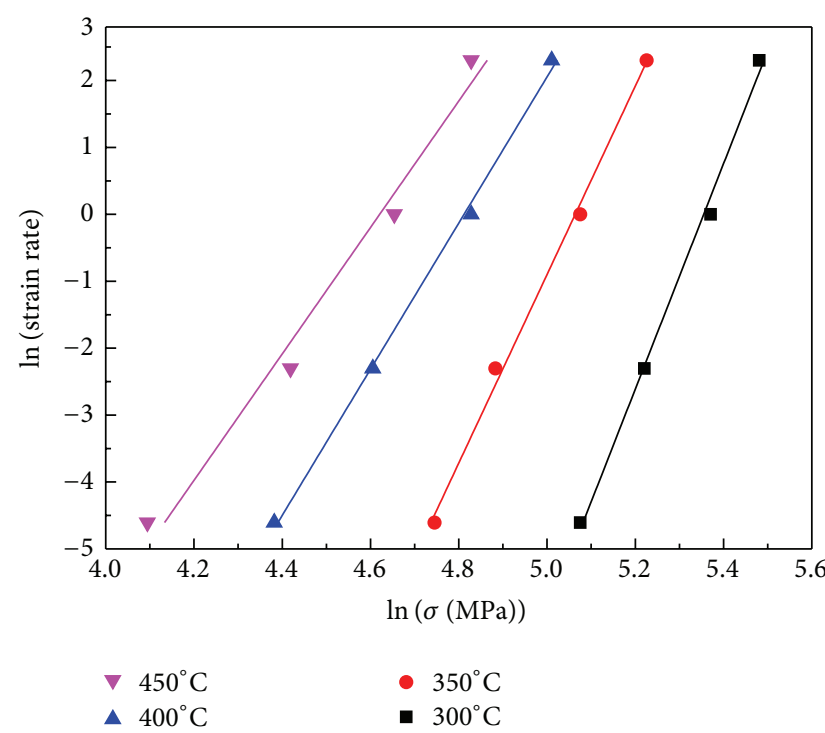

(a)

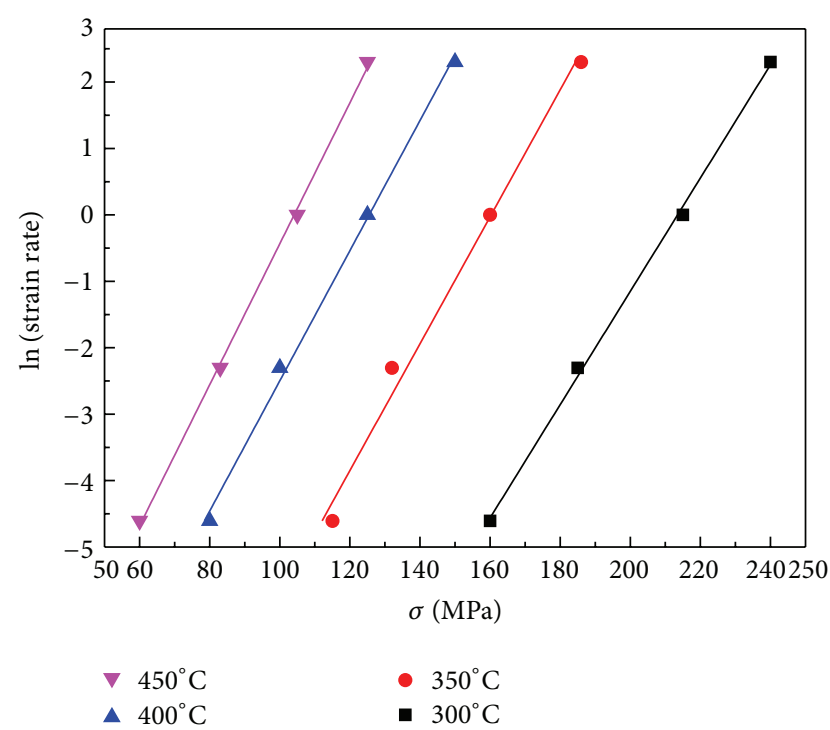

(b)

FIGURE 5: Relationships between strain rate and peak stresses: (a) $\ln \dot{\varepsilon}$ and $\ln \sigma$; (b) $\ln \dot{\varepsilon}$ and $\sigma$.

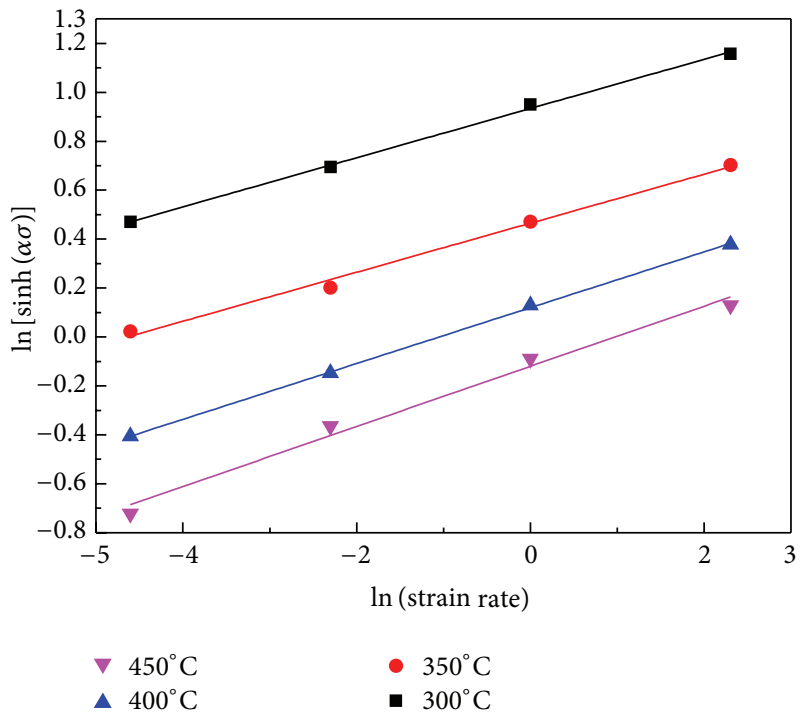

Figure 6: Relationship between $\ln [\sinh (\alpha \sigma)]$ and $\ln \dot{\varepsilon}$.

the influence of temperature on the flow stresses should be enforced here for the nature of $2026 \mathrm{Al}$ alloy.

Through numerous repeated calculations and validation, it is found that, to make the $Z$ parameter better conform to the real, (1) should multiply with $\exp (22.93975 X-135.508)$. So, the revised $Z^{\prime}$ parameter can be expressed as

$$
Z^{\prime}=\exp (22.93975 X-135.508) \dot{\varepsilon} \exp \left(\frac{Q}{R T}\right) \text {, }
$$

where factor $X$ represents the deformation temperature in ${ }^{\circ} \mathrm{C}$; it represents the influences of the temperature on the precipitation behavior of the alloy.

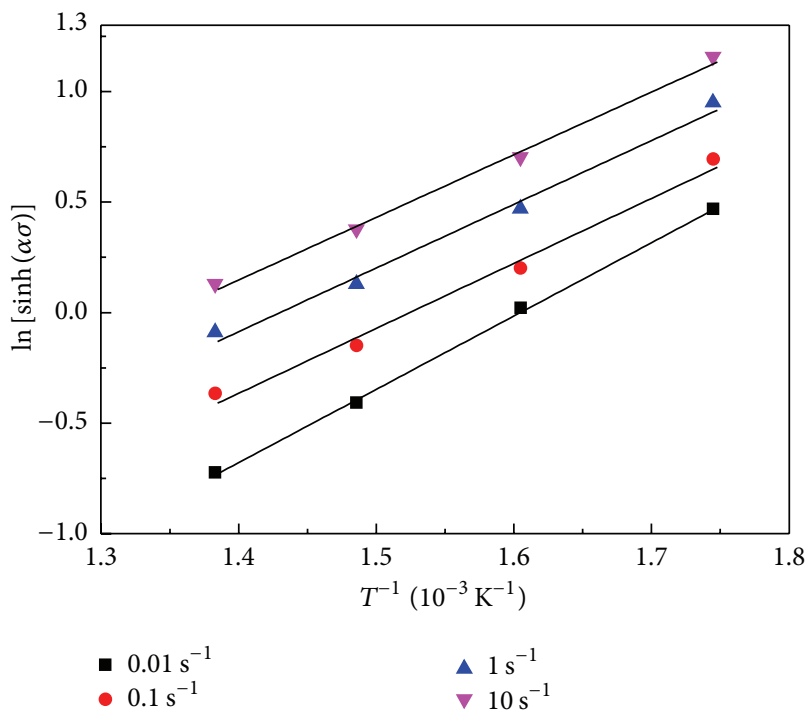

FIGURE 7: Relationship between $\ln [\sinh (\alpha \sigma)]$ and temperature.

Therefore, the flow stress constitutive equation expressed as (13) can be renewed as

$$
\sigma=\frac{1}{\alpha} \ln \left\{\left(\frac{Z^{\prime}}{A}\right)^{1 / n}+\left[\left(\frac{Z^{\prime}}{A}\right)^{2 / n}+1\right]^{1 / 2}\right\} .
$$

Parameters of $\alpha, n$, and $A$ in the equation are not changed as before, while $Z$ is the modified one from (16).

3.4. Verification of the Revised Constitutive Equation. Table 2 shows the comparisons between the peak stresses calculated from the revised constitutive equation and the experiment data. 
TABLE 1: Comparisons of the predicated $\left(\sigma_{P}\right)$ and measured $\left(\sigma_{E}\right)$ peak stress (unit: MPa) before the modification of $Z$ parameter.

\begin{tabular}{|c|c|c|c|c|c|c|}
\hline \multirow{2}{*}{ Strain rate $\left(\mathrm{s}^{-1}\right)$} & \multirow{2}{*}{ Temperature $\left({ }^{\circ} \mathrm{C}\right)$} & \multirow{2}{*}{$\sigma_{E}$} & \multirow{2}{*}{$\sigma_{P}$} & \multicolumn{3}{|c|}{ Error analysis } \\
\hline & & & & Error $(\%)$ & Mean (\%) & Standard deviation (\%) \\
\hline \multirow{4}{*}{0.01} & 300 & 160 & 239.18 & 49.49 & \multirow{4}{*}{29.20} & \multirow{4}{*}{19.42} \\
\hline & 350 & 115 & 126.34 & 9.86 & & \\
\hline & 400 & 80 & 67.53 & 15.58 & & \\
\hline & 450 & 72 & 41.85 & 41.87 & & \\
\hline \multirow{4}{*}{0.1} & 300 & 191 & 277.79 & 45.44 & \multirow{4}{*}{27.49} & \multirow{4}{*}{15.24} \\
\hline & 350 & 132 & 150.90 & 14.32 & & \\
\hline & 400 & 100 & 84.64 & 15.36 & & \\
\hline & 450 & 83 & 54.09 & 34.83 & & \\
\hline \multirow{4}{*}{1} & 300 & 228 & 318.32 & 39.61 & \multirow{4}{*}{25.35} & \multirow{4}{*}{13.74} \\
\hline & 350 & 160 & 177.83 & 11.14 & & \\
\hline & 400 & 125 & 104.57 & 16.34 & & \\
\hline & 450 & 105 & 68.99 & 34.30 & & \\
\hline \multirow{4}{*}{10} & 300 & 240 & 360.24 & 50.10 & \multirow{4}{*}{26.83} & \multirow{4}{*}{17.67} \\
\hline & 350 & 186 & 206.67 & 11.11 & & \\
\hline & 400 & 150 & 127.03 & 15.31 & & \\
\hline & 450 & 125 & 86.51 & 30.79 & & \\
\hline
\end{tabular}

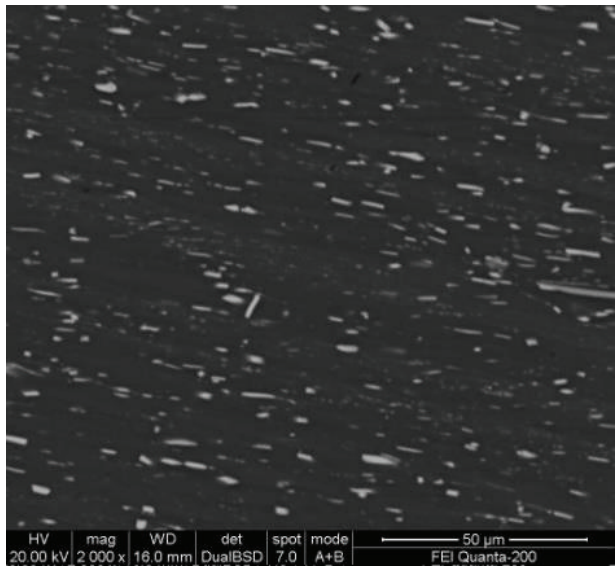

(a)

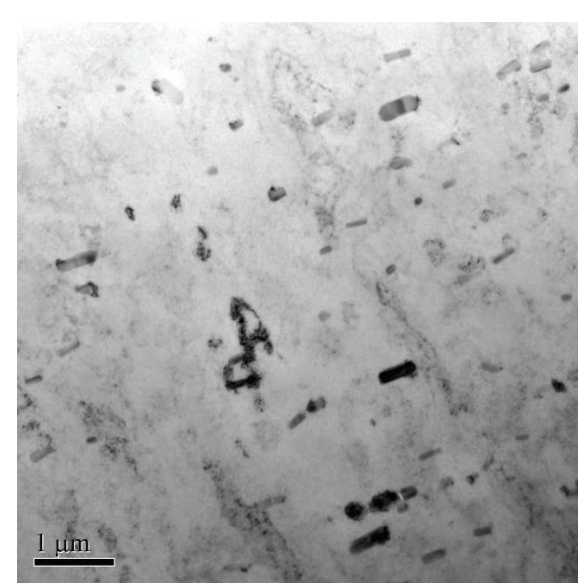

(b)

FIGURE 8: Microstructure after hot deformation at true strain of 0.6 with the deformation temperature of $350^{\circ} \mathrm{C}$ and strain rate of $1 \mathrm{~s}^{-1}:(\mathrm{a})$ backscattered electron image and (b) TEM micrograph.

As observed from the values, agreement between the calculated and measured values is good, and the maximum relative error is only $5.87 \%$. The results indicated that the modified $Z$ parameter can give a good estimate of the peak stresses for $2026 \mathrm{Al}$ alloy under different hot compression temperature and strain rate and can be used in guidance of the hot processing of $2026 \mathrm{Al}$ alloy.

\section{Conclusions}

In this study, the effects of deformation parameters on the true stress-strain behavior of $2026 \mathrm{Al}$ alloy were investigated. According to the experiment data, a constitutive equation incorporating the effects of strain rates and temperatures is obtained, while the errors between the experiment and predicated results range from $9.86 \%$ to $50.10 \%$. So a revised constitutive equation is derived by compensation of temperature considering the impact of the second phase on the true stress; a good agreement between the predicated and the experiment results indicated that the revised constitutive equation can give an accurate prediction of the peak stress for $2026 \mathrm{Al}$ alloy and can be used in the hot processing of the $2026 \mathrm{Al}$ alloy. In addition, pictures about the microstructures were obtained using scanning electron microscopy (SEM) and transmission electron microscopy (TEM) for verification and assistance.

\section{Competing Interests}

The authors declare that they have no competing interests. 
TABLE 2: Comparisons of the predicated $\left(\sigma_{P}\right)$ and measured $\left(\sigma_{E}\right)$ peak stress (unit: MPa) after the modification of $Z$ parameter.

\begin{tabular}{|c|c|c|c|c|c|c|}
\hline \multirow{2}{*}{ Strain rate $\left(\mathrm{s}^{-1}\right)$} & \multirow{2}{*}{ Temperature $\left({ }^{\circ} \mathrm{C}\right)$} & \multirow{2}{*}{$\sigma_{E}$} & \multirow{2}{*}{$\sigma_{P}$} & \multicolumn{3}{|c|}{ Error analysis } \\
\hline & & & & Error (\%) & Mean (\%) & Standard deviation (\%) \\
\hline \multirow{4}{*}{0.01} & 300 & 160 & 169.37 & 5.86 & \multirow{4}{*}{3.03} & \multirow{4}{*}{2.4} \\
\hline & 350 & 115 & 115.28 & 0.24 & & \\
\hline & 400 & 80 & 81.72 & 2.15 & & \\
\hline & 450 & 72 & 69.22 & 3.87 & & \\
\hline \multirow{4}{*}{0.1} & 300 & 191 & 202.22 & 5.87 & \multirow{4}{*}{4.14} & \multirow{4}{*}{2.03} \\
\hline & 350 & 132 & 138.54 & 4.96 & & \\
\hline & 400 & 100 & 101.21 & 1.21 & & \\
\hline & 450 & 83 & 86.76 & 4.53 & & \\
\hline \multirow{4}{*}{1} & 300 & 228 & 238.21 & 4.48 & \multirow{4}{*}{2.53} & \multirow{4}{*}{1.44} \\
\hline & 350 & 160 & 164.37 & 2.73 & & \\
\hline & 400 & 125 & 123.29 & 1.37 & & \\
\hline & 450 & 105 & 106.60 & 1.52 & & \\
\hline \multirow{4}{*}{10} & 300 & 240 & 246.77 & 2.82 & \multirow{4}{*}{2.62} & \multirow{4}{*}{0.72} \\
\hline & 350 & 186 & 192.33 & 3.40 & & \\
\hline & 400 & 150 & 147.50 & 1.66 & & \\
\hline & 450 & 125 & 128.22 & 2.58 & & \\
\hline
\end{tabular}

\section{Acknowledgments}

This work was supported by the National Program on Key Basic Research Project of China (no. 2012CB619504 and no. 2014CB046702). The authors thank Lin Y. C. and his coworkers in the School of Mechanical and Electrical Engineering, Central South University, Changsha, for their kind and helpful theoretical guidance and discussion.

\section{References}

[1] A. Łukaszek-Sołek and J. Krawczyk, "The analysis of the hot deformation behaviour of the Ti-3Al-8V-6Cr-4Zr-4Mo alloy, using processing maps, a map of microstructure and of hardness," Materials \& Design, vol. 65, pp. 165-173, 2015.

[2] T.-D. Kil, J.-M. Lee, and Y.-H. Moon, "Quantitative formability estimation of ring rolling process by using deformation processing map," Journal of Materials Processing Technology, vol. 220, pp. 224-230, 2015.

[3] S. Saadatkia, H. Mirzadeh, and J.-M. Cabrera, "Hot deformation behavior, dynamic recrystallization, and physically-based constitutive modeling of plain carbon steels," Materials Science and Engineering: A, vol. 636, pp. 196-202, 2015.

[4] H. Mirzadeh, J. M. Cabrera, and A. Najafizadeh, "Constitutive relationships for hot deformation of austenite," Acta Materialia, vol. 59, no. 16, pp. 6441-6448, 2011.

[5] M. El Mehtedi, F. Gabrielli, and S. Spigarelli, "Hot workability in process modeling of a bearing steel by using combined constitutive equations and dynamic material model," Materials \& Design, vol. 53, pp. 398-404, 2014.

[6] M. El Mehtedi, F. Musharavati, and S. Spigarelli, "Modelling of the flow behaviour of wrought aluminium alloys at elevated temperatures by a new constitutive equation," Materials and Design, vol. 54, pp. 869-873, 2014.

[7] T.-H. Pham, J. J. Kim, and S.-E. Kim, "Estimating constitutive equation of structural steel using indentation," International Journal of Mechanical Sciences, vol. 90, pp. 151-161, 2015.
[8] C.-L. Gan, K.-H. Zheng, W.-J. Qi, and M.-J. Wang, “Constitutive equations for high temperature flow stress prediction of 6063 Al alloy considering compensation of strain," Transactions of Nonferrous Metals Society of China (English Edition), vol. 24, no. 11, Article ID 63492, pp. 3486-3491, 2014.

[9] Y. Liu, Z. Yao, Y. Ning et al., "The flow behavior and constitutive equation in isothermal compression of FGH4096-GH4133B dual alloy," Materials and Design, vol. 63, pp. 829-837, 2014.

[10] X. Peng, H. Guo, Z. Shi, C. Qin, and Z. Zhao, "Constitutive equations for high temperature flow stress of TC4-DT alloy incorporating strain, strain rate and temperature," Materials and Design, vol. 50, pp. 198-206, 2013.

[11] Y. C. Lin and X.-M. Chen, "A critical review of experimental results and constitutive descriptions for metals and alloys in hot working," Materials \& Design, vol. 32, no. 4, pp. 1733-1759, 2011.

[12] D. Samantaray, C. Phaniraj, S. Mandal, and A. K. Bhaduri, "Strain dependent rate equation to predict elevated temperature flow behavior of modified 9Cr-1Mo (P91) steel," Materials Science and Engineering: A, vol. 528, no. 3, pp. 1071-1077, 2011.

[13] N. Haghdadi, A. Zarei-Hanzaki, and H. R. Abedi, "The flow behavior modeling of cast A356 aluminum alloy at elevated temperatures considering the effect of strain," Materials Science and Engineering A, vol. 535, pp. 252-257, 2012.

[14] B.-J. Lv, J. Peng, D.-W. Shi, A.-T. Tang, and F.-S. Pan, "Constitutive modeling of dynamic recrystallization kinetics and processing maps of $\mathrm{Mg}-2.0 \mathrm{Zn}-0.3 \mathrm{Zr}$ alloy based on true stressstrain curves," Materials Science and Engineering A, vol. 560, pp. 727-733, 2013.

[15] M. Zhou, Y. C. Lin, J. Deng, and Y.-Q. Jiang, "Hot tensile deformation behaviors and constitutive model of an $\mathrm{Al}-\mathrm{Zn}-$ Mg-Cu alloy," Materials \& Design, vol. 59, pp. 141-150, 2014.

[16] H. Mirzadeh, "Constitutive modeling and prediction of hot deformation flow stress under dynamic recrystallization conditions," Mechanics of Materials, vol. 85, pp. 66-79, 2015.

[17] C. M. Sellars, "The kinetics of softening processes during hot working of austenite," Czechoslovak Journal of Physics B, vol. 35, no. 3, pp. 239-248, 1985. 
[18] C. M. Sellars and W. J. McTegart, "On the mechanism of hot deformation,” Acta Metallurgica, vol. 14, no. 9, pp. 1136-1138, 1966.

[19] C. Zener and J. H. Hollomon, "Effect of strain rate upon plastic flow of steel," Journal of Applied Physics, vol. 15, no. 1, pp. 22-32, 1944.

[20] G. Z. Quan, Y. Tong, G. Luo, and J. Zhou, "A characterization for the flow behavior of 42CrMo steel," Computational Materials Science, vol. 50, no. 1, pp. 167-171, 2010.

[21] L.-Z. Wu, X.-S. Li, J. Chen, H.-B. Zhang, and Z.-S. Cui, "Predicting critical conditions and stress-strain curves for dynamic recrystallization in SPHC steel," Journal of Iron and Steel Research International, vol. 17, no. 7, pp. 51-57, 2010.

[22] I. Mejía, A. Bedolla-Jacuinde, C. Maldonado, and J. M. Cabrera, "Determination of the critical conditions for the initiation of dynamic recrystallization in boron microalloyed steels," Materials Science and Engineering: A, vol. 528, no. 12, pp. 41334140, 2011.

[23] N. Park, A. Shibata, D. Terada, and N. Tsuji, "Flow stress analysis for determining the critical condition of dynamic ferrite transformation in $6 \mathrm{Ni}-0.1 \mathrm{C}$ steel," Acta Materialia, vol. 61, no. 1, pp. 163-173, 2013.

[24] Y. C. Lin, M.-S. Chen, and J. Zhong, "Constitutive modeling for elevated temperature flow behavior of 42CrMo steel," Computational Materials Science, vol. 42, no. 3, pp. 470-477, 2008.

[25] Y. C. Lin, M.-S. Chen, and J. Zhong, "Microstructural evolution in 42CrMo steel during compression at elevated temperatures," Materials Letters, vol. 62, no. 14, pp. 2136-2139, 2008.

[26] Y.-C. Lin, M.-S. Chen, and J. Zhang, "Modeling of flow stress of 42CrMo steel under hot compression," Materials Science and Engineering: A, vol. 499, no. 1-2, pp. 88-92, 2009.

[27] Y. C. Lin, M.-S. Chen, and J. Zhong, "Numerical simulation for stress/strain distribution and microstructural evolution in 42CrMo steel during hot upsetting process," Computational Materials Science, vol. 43, no. 4, pp. 1117-1122, 2008.

[28] M. I. A. E. Aal, "Influence of the pre-homogenization treatment on the microstructure evolution and the mechanical properties of $\mathrm{Al}-\mathrm{Cu}$ alloys processed by ECAP,' Materials Science and Engineering: A, vol. 528, no. 22-23, pp. 6946-6957, 2011.

[29] J.-H. Jang, D.-G. Nam, Y.-H. Park, and I.-M. Park, "Effect of solution treatment and artificial aging on microstructure and mechanical properties of $\mathrm{Al}-\mathrm{Cu}$ alloy," Transactions of Nonferrous Metals Society of China, vol. 23, no. 3, pp. 631-635, 2013.

[30] C. Giummarra, G. H. Bray, and D. J. Duquette, "Fretting fatigue in 2XXX series aerospace aluminium alloys," Tribology International, vol. 39, no. 10, pp. 1206-1212, 2006.

[31] Y. Chen, M. Weyland, and C. R. Hutchinson, "The effect of interrupted aging on the yield strength and uniform elongation of precipitation-hardened Al alloys," Acta Materialia, vol. 61, no. 15, pp. 5877-5894, 2013.

[32] H. C. Fang, H. Chao, and K. H. Chen, "Effect of Zr, Er and Cr additions on microstructures and properties of $\mathrm{Al}-\mathrm{Zn}-\mathrm{Mg}-\mathrm{Cu}$ alloys," Materials Science and Engineering A, vol. 610, pp. 10-16, 2014.

[33] D. F. Lam, C. C. Menzemer, and T. S. Srivatsan, "A study to evaluate and understand the response of aluminum alloy 2026 subjected to tensile deformation," Materials \& Design, vol. 31, no. 1, pp. 166-175, 2010.

[34] X. Huang, H. Zhang, Y. Han, W. Wu, and J. Chen, "Hot deformation behavior of 2026 aluminum alloy during compression at elevated temperature," Materials Science and Engineering A, vol. 527, no. 3, pp. 485-490, 2010.

[35] F. J. Humphreys and M. Hatherly, "The deformed state," in Recrystallization and Related Annealing Phenomena, F. J. H. Hatherly, Ed., chapter 2, p. 11, Elsevier, New York, NY, USA, 2004.

[36] Z. Q. Sheng and R. Shivpuri, "Modeling flow stress of magnesium alloys at elevated temperature," Materials Science and Engineering A, vol. 419, no. 1-2, pp. 202-208, 2006.

[37] R. E. Smallman and R. J. BiShop, "Chapter 7-mechanical behaviour of materials," in Modern Physical Metallurgy and Materials Engineering, pp. 197-258, Butterworth-Heinemann, Boston, Mass, USA, 6th edition, 1999. 

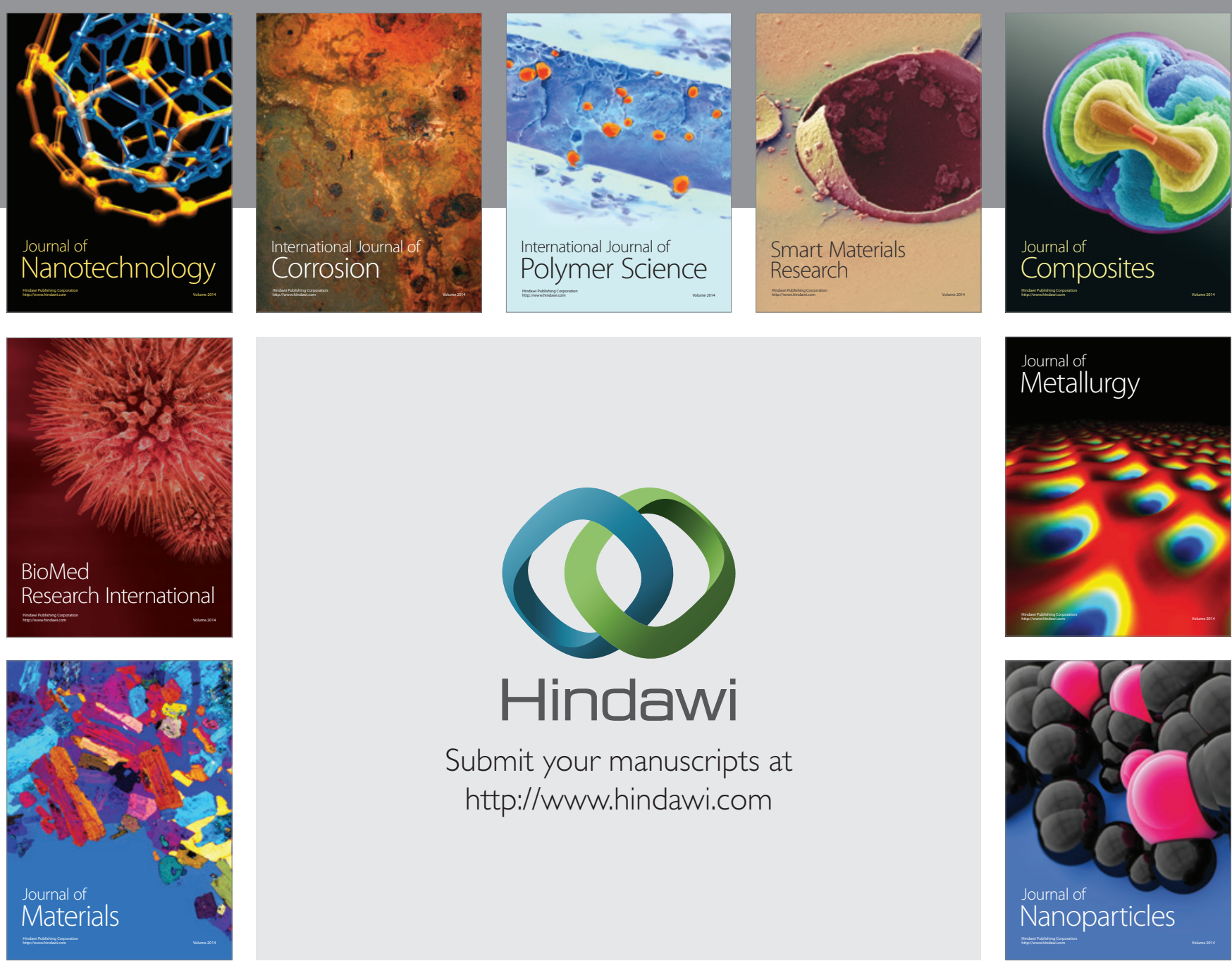

\section{Hindawi}

Submit your manuscripts at

http://www.hindawi.com

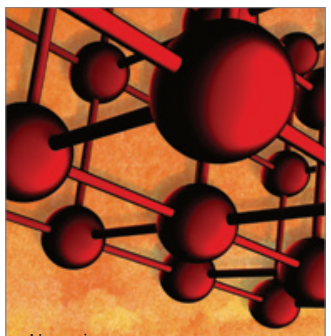

Materials Science and Engineering
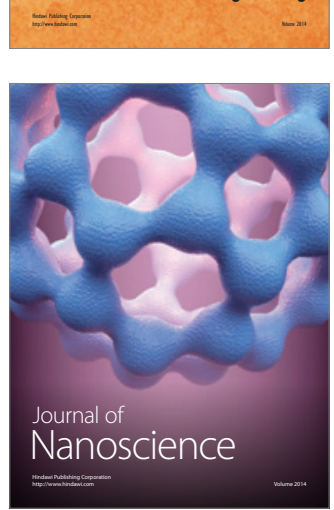
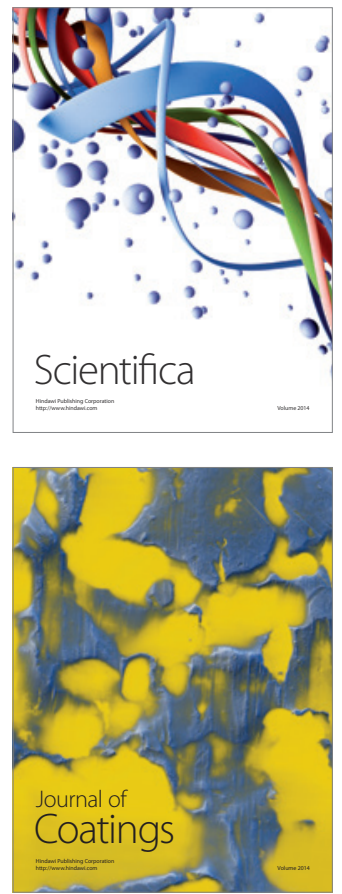
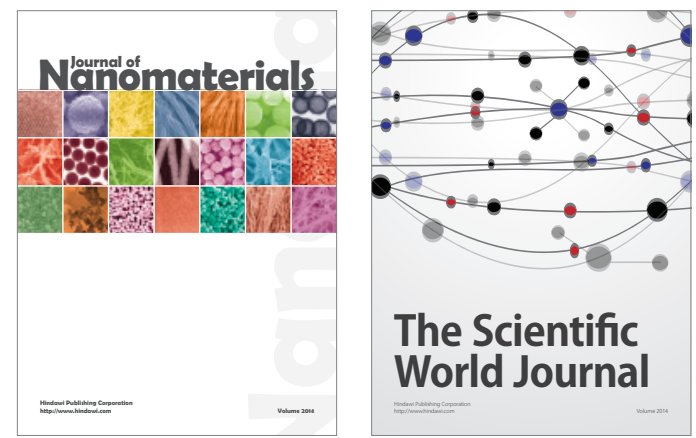

The Scientific World Journal
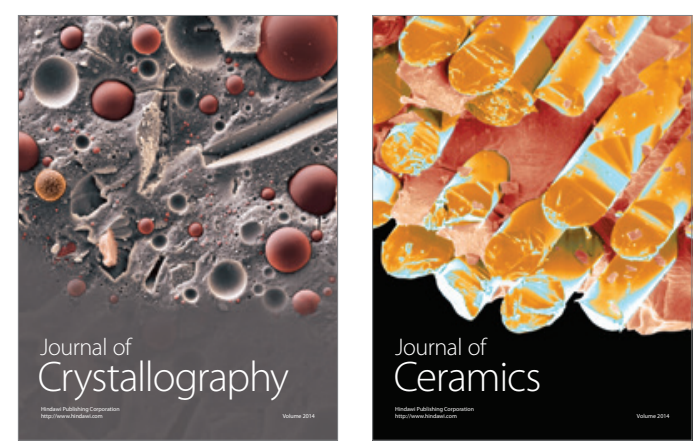
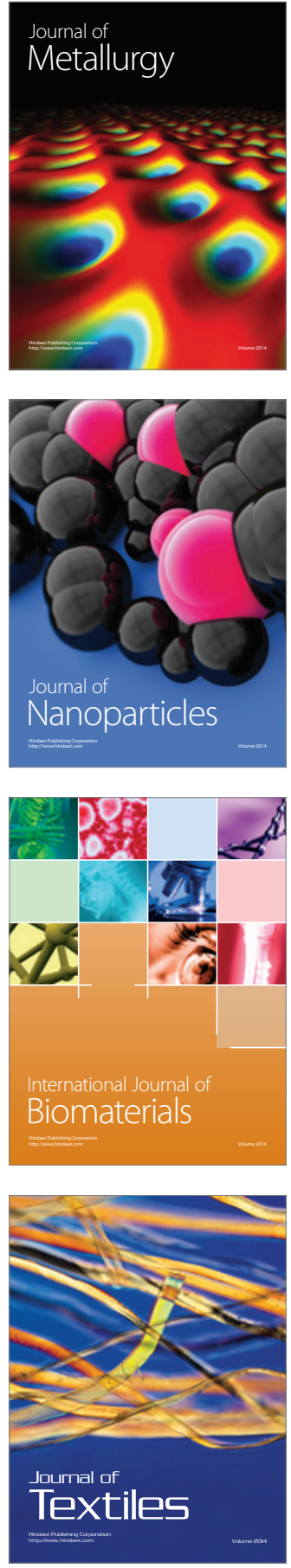